\title{
Genome-wide identification and expression analysis of new cytokinin metabolic genes in bread wheat (Triticum aestivum L.)
}

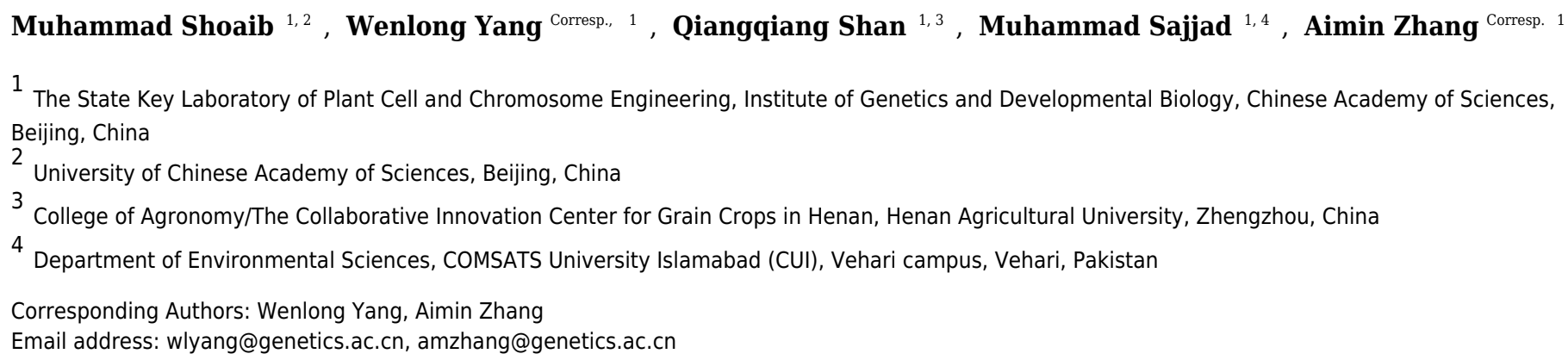

Cytokinins (CKs) are involved in determining the final grain yield in wheat. Multiple gene families are responsible for the controlled production of CKs in plants, including isopentenyl transferases for de novo synthesis, zeatin O-glucosyltransferases for reversible inactivation, $\beta$-glucosidases for reactivation, and CK oxidases/dehydrogenases for permanent degradation. Identifying and characterizing the genes of these families is an important step in furthering our understanding of CK metabolism. Using bioinformatics tools, we identified four new TaIPT, four new TaZOG, and 25 new TaGLU genes in common wheat. All of the genes harbored the characteristic conserved domains of their respective gene families. We renamed TaCKX genes on the basis of their true orthologs in rice and maize to remove inconsistencies in the nomenclature. Phylogenetic analysis revealed the early divergence of monocots from dicots, and the gene duplication event after speciation was obvious. Abscisic acid-, auxin-, salicylic acid-, sulfur-, drought- and light-responsive cis-regulatory elements were common to most of the genes under investigation.

Expression profiling of CK metabolic gene families was carried out at the seedlings stage in AA genome donor of common wheat. Exogenous application of phytohormones (6benzylaminopurine, salicylic acid, indole-3-acetic acid, gibberellic acid, and abscisic acid) for $3 \mathrm{~h}$ significantly upregulated the transcript levels of all four gene families, suggesting that plants tend to maintain CK stability. A 6- benzylaminopurine-specific maximum foldchange was observed for TUCKXI and TUCKX3 in root and shoot tissues, respectively; however, the highest expression level was observed in the TUGLU gene family, indicating that the reactivation of the dormant CK isoform is the quickest way to counter external stress. The identification of new CK metabolic genes provides the foundation for their indepth functional characterization and for elucidating their association with grain yield. 
1 Genome-wide identification and expression analysis of new cytokinin metabolic genes in bread wheat (Triticum aestivum L.)

4 Muhammad Shoaib ${ }^{1,2, \dagger}$, Wenlong Yang ${ }^{1, *}{ }^{*}$, , Qiangqiang Shan ${ }^{1,3}$, Muhammad Sajjad ${ }^{1,4}$, Aimin 5 Zhang ${ }^{1, *}$

$6{ }^{1}$ The State Key Laboratory of Plant Cell and Chromosome Engineering, Institute of Genetics

7 and Developmental Biology, Chinese Academy of Sciences, Beijing, China,

$8{ }^{2}$ University of Chinese Academy of Sciences, Beijing, China,

$9{ }^{3}$ College of Agronomy/The Collaborative Innovation Center for Grain Crops in Henan, Henan

10 Agricultural University, Zhengzhou, China

$11{ }^{4}$ Department of Environmental Sciences, COMSATS University Islamabad (CUI), Vehari

12 campus, Vehari, Pakistan,

$13 \dagger$ These authors contributed equally to the work.

14 *Corresponding authors: Wenlong Yang, wlyang@genetics.ac.cn, Aimin Zhang,

15 amzhang@genetics.ac.cn 


\section{Abstract}

18 Cytokinins $(\mathrm{CKs})$ are involved in determining the final grain yield in wheat. Multiple gene families are responsible for the controlled production of CKs in plants, including isopentenyl transferases for de novo synthesis, zeatin O-glucosyltransferases for reversible inactivation, $\beta$ 21 glucosidases for reactivation, and $\mathrm{CK}$ oxidases/dehydrogenases for permanent degradation. Identifying and characterizing the genes of these families is an important step in furthering our understanding of CK metabolism. Using bioinformatics tools, we identified four new TaIPT, four new TaZOG, and 25 new TaGLU genes in common wheat. All of the genes harbored the characteristic conserved domains of their respective gene families. We renamed $\operatorname{TaCKX}$ genes on the basis of their true orthologs in rice and maize to remove inconsistencies in the nomenclature. Phylogenetic analysis revealed the early divergence of monocots from dicots, and the gene duplication event after speciation was obvious. Abscisic acid-, auxin-, salicylic acid-, sulfur-, drought- and light-responsive cis-regulatory elements were common to most of the genes under investigation. Expression profiling of $\mathrm{CK}$ metabolic gene families was carried out at the seedlings stage in AA genome donor of common wheat. Exogenous application of phytohormones (6-benzylaminopurine, salicylic acid, indole-3-acetic acid, gibberellic acid, and abscisic acid) for $3 \mathrm{~h}$ significantly upregulated the transcript levels of all four gene families, suggesting that plants tend to maintain CK stability. A 6- benzylaminopurine-specific maximum fold-change was observed for $T u C K X 1$ and $T u C K X 3$ in root and shoot tissues, respectively; however, the highest expression level was observed in the $T u G L U$ gene family, indicating that the reactivation of the dormant $\mathrm{CK}$ isoform is the quickest way to counter external stress. The identification of new CK metabolic genes provides the foundation for their in-depth functional characterization and for elucidating their association with grain yield. 


\section{INTRODUCTION}

44 Wheat (Triticum aestivum L.) is the predominant cereal crop, second only to rice as the most important staple, with global production nearing 740 million tons of grain (USDA, 2017). The projected increase in the human population will increase the production demand to 900 million tons by 2050 (FAO stat 2016); thus, increasing the yield per unit area will be important for meeting this mounting challenge (Bartrina et al., 2011).

Recent studies in model plants have revealed that cytokinin $(\mathrm{CK})$ metabolic genes are strongly associated with plant yield (Ashikari et al., 2005; Bartrina et al., 2011). CKs are phytohormones that play key roles in regulating the vegetative and reproductive development of plants (Mok and Mok, 2001; Zalewski et al., 2010). Most CKs are adenine derivatives and have an isoprenoid or aromatic side chain attached to the N-6 of the purine ring (Avalbaev et al., 2012). trans-Zeatin-, cis-zeatin-, and dihydrozeatin-type CKs have also been reported in plants, but their abundance is species-specific (Sakakibara, 2006). Genetic manipulation of the genes involved in CK homeostasis can be used for yield improvement, as a significant change in CK content has been observed during grain development in crop plants, including wheat (Jameson et al., 1982) and rice (Ashikari et al., 2005). CK homeostasis is carried out by several gene families including isopentenyl transferases (IPTs) for biosynthesis, zeatin O-glucosyltransferases (ZOGs) for reversible inactivation, $\beta$-glucosidases (GLUs) for reactivation, and cytokinin oxidases/dehydrogenases (CKXs) for degradation (Song et al., 2012).

IPTs are the gene family responsible for CK synthesis. Two possible pathways of CK synthesis have been proposed: (1) degradation of transfer RNA (tRNA) and (2) de novo synthesis. The first pathway is catalyzed by tRNA IPTs (EC 2.5.1.8); However, it is not considered as a major source of CK production (Takei et al., 2001). De novo biosynthesis of CKs is carried out by adenylate IPTs (EC 2.5.1.27) by adding an isopentenyl group to the N6 terminal domain of ATP (Frébort et al., 2011). To date, nine, eight, 11, and six IPT genes have been reported in Arabidopsis, rice, maize, and wheat, respectively (Chang et al., 2015; Song et al., 2012). Kakimoto (2001) examined the expression of AtIPT gene family and demonstrated that AtIPT3, AtIPT5 and AtIPT7 were expressed in all the tissues, whereas AtIPT6 and AtIPT1 were only expressed in the siliques. Moreover, in maize, the tRNA-IPT genes ZmIPT1 and ZmIPT10 were reportedly highly expressed in all the organs, whereas the expression patterns of the 
73 remaining ZmIPT genes were spatially and temporally specific (Vyroubalová et al., 2009). In 74 wheat, TaIPT2, TaIPT5, and TaIPT8 are expressed during the reproductive stage, and TaIPT2

75 76 exhibits the highest expression level (Song et al., 2012). Controlled expression of IPT genes can be used to improve plant growth and development (Faiss et al., 1997). Transgenic plants harboring a high molecular weight gluten promoter fused with an IPT gene (HMWipt) exhibited increased seed weight (Daskalova et al., 2007). IPT protein production under the control of the $P_{S A R K}$ promoter in transgenic peanuts led to drought tolerance, delayed senescence and most importantly, a 51-65\% increase in seed yield compared with the wild type (Qin et al., 2011).

Zeatin, an active form of CK, was first identified in maize. Glycosylation of zeatin to Oglucosyl-zeatin and O-xylosyl-zeatin is carried out by ZOG and O-xylosyl transferase (ZOX), respectively (Martin et al., 1999). To date, three ZOG genes in Arabidopsis, three in wheat and several ZOG genes in maize have been identified (Song et al., 2012). O-glucosylation of zeatintype CKs is reversible in nature. The deglycosylation of zeatin type CKs is catalyzed by GLU (Brzobohaty et al., 1993). GLU genes are the members of the glycoside hydrolase 1 family and are involved in the regulation of CK metabolism (Song et al., 2012). In Arabidopsis and rice, 47 (Miyahara et al., 2011) and 37 (Sasaki et al., 2002) GLUs have been annotated, respectively, whereas in wheat only six TaGLU genes have been identified thus far (Song et al., 2012). The substrate specificity of GLU was found to be conserved in ZOGs (Falk and Rask, 1995). As de novo synthesis of $\mathrm{CK}$ is slow, it is likely that reversible degradation and activation of CKs play important roles in maintaining the total CK pool in plants (Frébort et al., 2011).

CKXs (EC: 1.5.99.12) are the only enzymes that permanently degrade CKs by cleaving the N6-unsaturated side chain of the CK to adenine and adenosine in a single step (Ma et al., 2011). Two conserved domains involved in the catalytic activity of CKXs have been reported, a FAD binding domain at the $\mathrm{N}$ terminus and a $\mathrm{CK}$ binding domain at the $\mathrm{C}$ terminus of the protein (Avalbaev et al., 2012). Pačes et al. (1971) first reported CKX activity in tobacco, whereas the first CKX gene ( $\mathrm{ZmCKXI})$ was isolated from maize (Houba-Hérin et al., 1999). Since then, many CKX genes have been identified in multiple plant species (Galuszka et al., 2000). To date, seven CKX genes from Arabidopsis, 11 from rice, 13 from maize and 13 from wheat have been partially or completely identified (Lu et al., 2015; Song et al., 2012). As CKX is a multi-gene family, every member of the family is expected to have specific biochemical properties (Yeh et al., 2015), i.e., organ localization, subcellular localization, and substrate specificity. Using gain- 
104 or loss-of-function methods, all of the $A t C K X$ genes have been functionally studied (Zalabák et 105 al., 2013). Detailed expression analysis of $H v C K X$ genes has suggested that $H v C K X 1, H v C K X 4$, $106 H v C K X 9$ and $H v C K X 11$ are more highly expressed in developing kernels, and by using RNA 107 interference technology, $H v C K X-1$ - and $H v C K X 9$-silenced plants were found to produce more spikes and a greater number of seeds (Zalewski et al., 2014).

In rice, the production of more $\mathrm{CK}$ as a result of reduced ${ }_{s} C K X 2$ expression increased the 110 total yield by increasing the number of reproductive organs (Ashikari et al., 2005). Yeh et al. 111 (2015) used short hairpin RNA-mediated silencing technology to hinder the expression of $112 O_{s} C K X 2$ in rice, resulting in an increased number of tillers and increased grain weight. Based on 113 quantitative expression analysis, 12 bread wheat varieties varying in the numbers of grains per 114 spike were found, and the variation was positively correlated with $\operatorname{TaCKX} 2.1$ and $\mathrm{TaCKX} .2$ 115 genes (Zhang et al., 2011). TaCKX6a02-D1a, an allelic isoform of TaCKX6a02-D1, was 116 correlated with grain size, grain weight and grain filling rate. These results were also confirmed 117 in 169 recombinant inbred lines (Jing $411 \times$ Hongmangchun 21) and 102 wheat varieties under 118 different environmental conditions. A 29-bp insertion-deletion mutation in the $3^{\prime}$ untranslated 119 region was thought to be responsible for this variation. In another experiment, copy number 120 variation in the TaCKX4 gene linked to Xwmc169 on chromosome 3AL was associated with 121 grain weight (Chang et al., 2015; Lu et al., 2015).

122 In summary, all members of the aforementioned CK metabolic gene families have been 123 identified in model plants, and in-depth functional studies have been carried out. Nevertheless, 124 the gene family members have not yet been completely identified in wheat. The hexaploidy 125 (AABBDD $=42)$, large genome size $(\sim 17 \mathrm{~GB})$ and complexity of interactions between the three 126 genomes are among the reasons for this lack of information. In this study, we explored new 127 genes belonging to the major CK metabolic families in wheat, laying a foundation for their 128 detailed characterization.

\section{MATERIALS AND METHODS}

131 Plant material

132 Triticum urartu seeds treated with $1 \% \mathrm{H}_{2} \mathrm{O}_{2}$ were grown in petri dishes. After 5 days, the 133 seedlings were transferred to hydroponic tanks and grown in controlled conditions $\left(25^{\circ} \mathrm{C}, 16: 8 \mathrm{~h}\right.$ 134 photoperiod). Half-strength Hoagland solution (Hoagland, D. R., \& Arnon, D. I. 1938) modified 
135 for solution culture was provided, and the nutrient solution was changed twice a week during the 136 course of the experiment. Fifteen days after germination, seedlings were treated with plant

137 hormones: $5 \mu \mathrm{M}$ 6-benzylaminopurine (6-BA), $0.5 \mathrm{mM}$ salicylic acid (SA), $10 \mu \mathrm{M}$ indole-3138 acetic acid (IAA), $30 \mu \mathrm{M}$ gibberellic acid $\left(\mathrm{GA}_{3}\right.$ ), and $10 \mu \mathrm{M}$ abscisic acid (ABA) for $3 \mathrm{~h}$, along 139 with the control treatment. A total of 20 seedlings per biological replicate and three biological 140 replicates per treatment were used. Immediately after $3 \mathrm{~h}$ treatment, root and shoot tissues were 141 collected and frozen in liquid nitrogen for RNA extraction.

\section{RNA extraction and cDNA synthesis}

144 Conventional RNA extraction was performed using TRIzol reagent (TIANGEN Biotech Co., 145 Ltd., Beijing, China) (Chomczynski \& Sacchi, 2006). The purity and quality of the RNA samples 146 were verified using 1\% agarose gel electrophoresis. For cDNA synthesis, $1.5 \mu \mathrm{g}$ of the RNA 147 template was used in a reaction mixture of $20 \mu \mathrm{L}$. A FastQuant RT kit (with gDNase) 148 (TIANGEN Biotech Co., Ltd.) was used according to the manufacturer's instructions, with the 149 final incubation time extended to $30 \mathrm{~min}$ at $42^{\circ} \mathrm{C}$.

150

\section{Isolation of CK metabolic genes}

152 To retrieve new members of the gene families involved in CK metabolism, the homology search 153 approach was used. cDNA sequences and the conserved domains of all previously annotated 154 genes involved in CK metabolism, i.e., IPTs, CKXs, GLUs, and ZOGs from Arabidopsis, maize, 155 and rice, were used to query the wheat database 156 (https://urgi.versailles.inra.fr/blast_iwgsc/blast.php). Matched sequences having E-values $\leq 2 \mathrm{e}^{-7}$ 157 were downloaded. A separate preliminary sequence alignment and a phylogenetic tree for each 158 gene family were constructed to clean the duplicate sequences. Using a BLASTx search of the 159 NCBI database (https://www.ncbi.nlm.nih.gov/), protein structures and conserved motifs specific 160 to each protein family were confirmed. The theoretical isoelectric points (PIs), molecular weights 161 (MWs) (http://web.expasy.org/compute_pi/), and N-glycosylation sites 162 (http://www.cbs.dtu.dk/services/NetNGlyc/) of CK metabolic proteins were also determined. 


\section{Gene structure and phylogenetic analysis}

165 The structures of $\mathrm{CK}$ metabolic gene families and the number of introns and exons were 166 determined using the Gene Structure Display Server (http://gsds.cbi.pku.edu.cn) (Hu et al.,

167 2015). For phylogenetic analysis, translated amino acid sequences were used, as protein 168 sequences are more conserved among species. Separate ClustalW multiple alignments 169 (Thompson, Higgins \& Gibson, 1994) of the protein sequences for each gene family were carried 170 out using Bioedit software (Hall, 1999). Based on the conserved domains and full-length protein 171 sequences, an unrooted neighbor-joining phylogenetic tree (bootstrap 1,000) was developed 172 using Geneious software (Kearse et al., 2012).

173

\section{In silico promoter analysis}

175 To identify cis-regulatory elements in the promoter regions of gene families involved in CK 176 metabolism, 2-kb upstream regions of the translation sites of the respective genes were extracted 177 from the local wheat genomic database. In silico promoter analysis was carried out for all the 178 reported genes of the respective multi-gene families. Cis-regulatory elements responsive to light, 179 phytohormones, abiotic stress, heat shock and low temperature were considered. MatInspector 180 software (Cartharius et al., 2005) based on the PLACE library 181 (http://www.dna.affrc.go.jp/PLACE/) (Higo et al., 1999) was used to explore the cis-regulatory 182 elements.

183

\section{Quantitative expression analysis}

185 As there was significant sequence similarity in the exonic regions of wheat sub-genomes, gene186 specific homoeologous quantitative polymerase chain reaction (qPCR) primers for all members 187 of the TaCKX, TaIPT, and TaZOG families were developed. As TaGLU is a large family, qPCR 188 primers were designed from selected family members (seven new and seven old genes). The 189 Ta4045 primer was used as an internal control (Paolacci et al., 2009), and SYBR Green I Master 190 Mix (Roche Diagnostics, Indianapolis, IN, USA) was used in the reaction mixture according to 191 the manufacturer's instructions. qPCR was conducted using the LightCycler 480 system (Roche 192 Diagnostics), with an initial denaturation step at $94^{\circ} \mathrm{C}$ for $5 \mathrm{~min}$, followed by 45 cycles of 193 denaturation at $94^{\circ} \mathrm{C}$ for $10 \mathrm{~s}$, annealing at $58^{\circ} \mathrm{C}$ for $10 \mathrm{~s}$, and extension at $72^{\circ} \mathrm{C}$ for $20 \mathrm{~s}$. Three 
194 biological and two technical replicates were used to reduce the error. Genes with reliably 195 detectable expression are presented here.

\section{Statistical analysis}

198 The $2^{-\Delta \Delta \mathrm{Ct}}$ method was used to calculate the relative expression levels for each treatment (Livak

$199 \&$ Schmittgen, 2001). Student's $t$-test was used to determine the significant differences in the 200 expression levels between the control and treated samples. All statistical analyses were carried 201 out using Microsoft Excel software.

202

203

\section{RESULTS}

\section{Bioinformatics analysis of CK metabolic genes}

205 Following in-depth mining of the wheat genomic database, $13 \mathrm{TaCKX}$, seven TaZOG, nine 206 TaIPT, and 32 TaGLU genes were identified (Fig. 1A-D). With few exceptions, most of the

207 identified genes had homoeologues in the A, B, and D sub-genomes; whereas the CKX gene 208 family members $T a C K X 12$ and $T a C K X 13$, the IPT gene family member TaIPT4, and the GLU 209 family member TaGLU21 did not have homoeologues. In wheat, CK metabolic genes were not 210 uniformly distributed among and along the lengths of chromosomes (Fig. 2). Most of the genes 211 resided away from the centromere towards the distal parts and formed CK metabolic gene-rich 212 regions. The maximum number of $\mathrm{CK}$ metabolic genes were found on chromosome groups three 213 and two, whereas only one gene ( $\operatorname{TaCKX7)}$ was found on chromosome group six. None of the 214 members of the TaCKX or TaIPT gene families were found on chromosome group four, nor were 215 any TaIPT genes found on chromosome group six. As TaZOG is a small gene family, its 216 members resided only on chromosome groups two, three, five and seven. TaGLU genes were 217 distributed on all the chromosomes except chromosome group six. Based on wheat reference 218 sequence 1.0, homoeologues of TaCKX11 and TaZOG2 were predicted on an unknown 219 chromosome. cDNA sequences of these homoeologues were BLASTed against Aegilops tauschii 220 in the Ensemble database and more than 90\% homology was found for the respective genes. 221 Based on this, we predicted that these homoeologues belong to the $\mathrm{D}$ genome.

222 Phylogenetic analyses were conducted for each gene family using previously reported 223 Arabidopsis, rice, maize, and wheat genes. The results showed that most of the identified genes 
224 from wheat had orthologs in other monocot species, that is why CK metabolic genes in wheat 225 were given names according to their homology in related species (Fig. 3A-D).

226 We were unable to identify new putative genes in the TaCKX gene family, as all of the 227 sequences were identical to previously identified TaCKXI-11 genes (Feng et al., 2008; Ma et al., 228 2011; Song et al., 2012; Zhang et al., 2007). However, we report the full-length in silico 229 extraction of the $\operatorname{TaCKX}$ gene family and rectification of its nomenclature. In the literature, 230 multiple names for a single $T a C K X$ gene sequence were observed (Table 1). We have renamed 231 the $\operatorname{TaCKX}$ gene sequences according to their homology with rice and maize (Fig. 3A). 232 According to this systematic renaming, the TaCKX gene family consists of 13 members, with 233 gene structures varying from 0 to 4 introns (Fig. 4A), predicted protein lengths of 516-555 234 amino acids (aa), PIs of 5.62-8.68, 0-5 glycosylation sites, and MWs ranging from 55.7 to 59.8 $235 \mathrm{kDa}$ (Table 2A). Phylogenetic analysis also revealed a D genome-specific duplication of the $236 T a C K X 2$ gene, forming a cluster (Fig. 3A) with more than $85 \%$ sequence similarity.

237 While mining the database for TaZOG, TaIPT and TaGLU gene families, four new 238 TaZOGs (TaZOG1, TaZOG2, TacisZOG3 and TacisZOG4), four new TaIPTs (TaIPT1, TaIPT4, 239 TaIPT9 and TaIPT10) and 25 new TaGLU genes were identified (Fig. 1B-D).

240 In the TaZOG gene family, with the exception of TaZOG2, remainder of the TaZOG genes 241 consisted of open reading frames (ORFs) with no introns (Fig. 4B). Exploring their predicted 242 proteins revealed lengths of 467-551 aa, PIs of 5-6.93, and MWs of 50.6-59.3 kDa. Most of the 243 TaZOG proteins were predicted to be localized to the plasma membrane, whereas the cis-type 244 ZOG proteins were anticipated to be secretory in nature (Table 2B). Genes in the TaIPT gene 245 family were also ORFs with no introns, except TaIPT9 (Fig. 4C). The predicted protein lengths 246 of TaIPT genes ranged from 292 to 499 aa, expected MWs from 31.6 to $52.1 \mathrm{kDa}$, and PIs from 2475.05 to 9.24, and the N-glycosylation sites of TaIPTs varied from 0 to 1 (Table 2C). Other than 248 the tRNA IPT genes (TaIPT9 and TaIPT10), the rest were predicted to localize to the chloroplast. 249 In contrast to the IPT family, the GLUs constitute a large gene family. The 25 predicted 250 TaGLU genes contained a minimum of 10 introns (Fig. 4D), and the predicted protein size for all $251 T a G L U$ genes varied from 406 to 585 aa. Glycosyl hydrolase family $1 / \beta$-glucosidase appeared to 252 be the characteristic conserved domain of this family, and the MW was predicted to range from 25346.1 to $64.6 \mathrm{kDa}$. Via in silico localization, most of the newly identified $T a G L U$ s appeared to be 254 chloroplastic in nature (Table 2D). As wheat is a monocot, newly predicted TaGLU genes were 
255 homologous to rice rather than the dicot Arabidopsis, and this characteristic was clearly mirrored

256 in the phylogenetic analysis of the GLU family (Fig. 3D).

257

\section{In silico promoter analysis}

259 Promoter analysis of the CK metabolic gene families revealed that drought-responsive ciselements were common to the promoter regions of all members of the TaIPT, TaZOG, TaGLU and $\operatorname{TaCKX}$ gene families (Table 3A, 3B, 3C and 3D). ABA- and sulfur-responsive cis-elements were common to members of the TaCKX and TaZOG families only (Table 3A and 3B), and coldresponsive cis-elements were only found in the promoter regions of $T a G L U$ genes (Table 3D).

\section{Expression analysis}

To determine which of the CK biosynthetic and degrading genes were highly expressed or responsive to phytohormones and abiotic stress, the expression patterns of the treated samples were recorded. Genes with reliably detectable expression are presented here. The experiment was conducted on AA genome donor (Triticum urartu) of hexaploid wheat. As a basic genome, it has played a central role in wheat evolution and the domestication process (Ling et al., 2013).

In general, with the application of phytohormones, the transcript levels of all the genes under study were upregulated as compared to the control treatment, except for TuGLU4, TuGLU9, and TuGLU12, as in roots; their expression levels were drastically lower than that of control treatment (Fig. 5A-D).

As all the gene families under study are involved in CK metabolism, majority of the genes,

with few exceptions, showed significant maximal changes in their transcript levels following exogenous $\mathrm{CK}$ treatment. Following $\mathrm{CK}$ treatment, most of the genes were responsive to $\mathrm{GA}_{3}$ treatment, as $\mathrm{GA}_{3}$ is also a major plant growth regulator; however, their transcript levels varied. While exploring the response of $\mathrm{CK}$ metabolic gene families to ABA treatment, we observed that the mRNA contents of TuGLU3 and TuGLU13 in leaf tissues only were significantly higher than those in control plants (Fig. 5B \& 5D).

For the $T u C K X$ gene family, the highest expression level in leaf tissue was recorded for $T u C K X 9$ (Fig.5A). In shoots and roots, $T u C K X 3$ and $T u C K X 1$, respectively, showed 6BAspecific maximum fold-changes in their expression patterns (Fig.5A and 5B). In the TuIPT gene 
286 the newly identified TuIPT10 exhibited maximum transcript abundance and was more highly 287 expressed in shoot tissues than in root tissues (Fig.5A and 5B). In the TuZOG family, TuZOG3

288 had the highest expression levels and a significant 6BA-specific response in T. urartu roots 289 (Fig.5A).

$290 T u G L U$ s are responsible for the reactivation of reversibly inactivated CKs, and this gene 291 family appeared to be more highly expressed than TuCKXs, TuIPTs, or TuZOGs. Among the 292 TuGLUs, TuGLU7 had the highest transcript level in shoot and root tissues; however, it was 293 significantly responsive to phytohormones only in shoots (Fig. 5B, 5D and Fig. 6B). In contrast, $294 T u G L U 1$ appeared to have a root-specific expression and 6BA-specific response (Fig.5D).

295

\section{DISCUSSION}

297 CKs are phytohormones that play important role in the regulation of plant growth. Their role in 298 cell differentiation, nutrient signaling, and leaf senescence have been well established (Yeh et al., 2015). Multigene families are reported to maintain CK homeostasis for normal plant growth. In model plants, the genes responsible for CK metabolism have already been identified and well characterized. Using a comparative genomics approach, the conserved domains and full-length coding sequences of CK anabolic (IPT and GLU) and catabolic (ZOG and CKX) genes from Arabidopsis, rice, and maize were used as queries to search the wheat local genomic database.

304 We were unable to identify new genes in the wheat TaCKX family. However, for the TaZOG, $T a I P T$, and $T a G L U$ gene families, we report four, four, and 25 new genes, respectively.

Naming newly identified genes on the basis of their orthologs in closely related species is a systematic way forward (Lee, Redfern \& Orengo, 2007), as inconsistencies in nomenclature can be misleading (Goyal et al., 2018). When reviewing the literature, some irregularities were found in the nomenclature of the $T a C K X$ gene family, i.e., multiple naming of homoeologues or single naming of different paralogs (Table 1). The polyploid nature of common wheat and the unavailability of its reference sequence until recently may have led to this discrepancy. In this work, a systematic approach was followed and $\operatorname{TaCKX}$ gene family members were renamed according to their true orthologs in rice and maize.

314 Phylogenetic analysis on the basis of sequence similarity is a powerful tool to predict 315 orthologous genes of interest and their functions in important crop species (Song et al., 2012).

316 AtIPT2 from Arabidopsis, ZmIPT1 from maize, and OsIPT9 from rice are actually tRNA IPT 
317 genes responsible for the synthesis of zeatin-type CKs in their respective species (Brugiere et al.,

318 2008; Miyawaki et al., 2006; Sakamoto et al., 2006). Based on the sequence and gene structure

319 similarities, newly identified TaIPT9 in wheat may have a similar function. Phylogenetic

320 analysis also revealed that newly identified $T a G L U$ genes from wheat are more similar to rice

321 than Arabidopsis, depicting the early divergence of monocots from dicot species.

322 Softberry and NetNGlyc servers were used to predict subcellular localization and 323 glycosylation sites, respectively. Variable subcellular localization and the presence or absence of 324 glycosylation sites within members of each family predicts their variable functions and substrate 325 specificities (Köllmer et al., 2014), which will later be confirmed practically. For example, 326 TaIPT9, which produces zeatin-type CKs, is predicted to localize to the cytoplasm, in contrast with the remainder of the TaIPT genes, which are predicted to localize to chloroplasts.

328 By controlling the efficiency of gene promoters, cis-regulatory elements contribute 329 significantly to the regulation of gene expression. Identifying the targeted cis-elements can aid in 330 devising detailed functional studies. Among the putative regulatory elements, ABA-, auxin-, SA331 , sulfur-, drought- and light-responsive cis-regulatory elements were predicted in most of the 332 promoters of $T a C K X, T a I P T, T a G L U$ and TaZOG genes. The broad range of regulatory elements 333 predicts their expression in multiple plant tissues, which may help these gene families stabilize 334 CK content under different environmental stresses.

335 Before moving forward and carrying out detailed studies of the newly predicted genes, it is necessary to characterize them practically based on expression levels and responsiveness to different stimuli. T. urartu seedlings grown under exogenous application of 6-BA, SA, GA, IAA and ABA hormones were used to develop expression profiles of the above-mentioned gene families. In general, after $3 \mathrm{~h}$ of treatment, the transcript levels of all $\mathrm{CK}$ metabolic genes were upregulated compared to the control treatment. With the application of external stimuli, CKX genes readily began to degrade active CK. To maintain homeostasis of the CK pool, by feedback

342 mechanism, genes for biosynthetic activity were also triggered. As de novo synthesis of CK is 343 relatively slow (Frébort et al., 2011), de-glycosylation of O-glycosylated CKs plays a major role 344 in stabilizing CK level (Vyroubalová et al., 2009). This can be explained by the higher 345 expression level of TuGLU genes compared to those of TuIPT genes (Fig. 5A-D). In contrast to

346 the high expression levels of $T u G L U$ genes in leaves and roots under external stimuli, the 347 transcript levels of TuGLU4, TuGLU9, and TuGLU12 were antagonistic in both tissues (Fig. 5A- 
348 D). This can be explained by the tissue-specific expression/function of CK metabolic genes

349 (Vyroubalová et al., 2009).

350 In conclusion, we predicted four new TaZOG, four new TaIPT, and 25 new TaGLU genes

351 in wheat and evaluated their sensitivity towards phytohormones. Future studies will be able to

352 mine their biochemical and functional characteristics and their associations with target traits in 353 crop plants.

\section{ACKNOWLEDGEMENTS}

356

357

358

359

360

361

362

363

364

365

366

367

368

369

370

371

372

373

374

375

376

377

378

We extend our gratitude to Drs. Linhe Sun, Dongcheng Liu, Jiazhu Sun, Xiaoling Ma and Mr.

Dongzhi Wang from Institute of Genetics and Developmental Biology, Chinese Academy of Sciences and to Dr. Kehui Zhan from College of Agronomy, Henan Agricultural University, for their help with material preparation and manuscript revision.

\section{REFERENCES}

Ashikari M, Sakakibara H, Lin S, Yamamoto T, Takashi T, Nishimura A, Angeles ER, Qian Q, Kitano H, and Matsuoka M. 2005. Cytokinin oxidase regulates rice grain production. Science 309: 741-745.

Avalbaev A, Somov K, Yuldashev R, and Shakirova F. 2012. Cytokinin oxidase is key enzyme of cytokinin degradation. Biochemistry (Moscow) 77: 1354-1361.

Bartrina I, Otto E, Strnad M, Werner T, and Schmülling T. 2011. Cytokinin regulates the activity of reproductive meristems, flower organ size, ovule formation, and thus seed yield in Arabidopsis thaliana. Plant Cell 23: 69-80.

Brugiere N, Humbert S, Rizzo N, Bohn J, and Habben JE. 2008. A member of the maize isopentenyl transferase gene family, Zea mays isopentenyl transferase 2 (ZmIPT2), encodes a cytokinin biosynthetic enzyme expressed during kernel development. Plant Molecular Biology 67: 215-229.

Brzobohaty B, Moore I, Kristoffersen P, Bako L, Campos N, Schell J, and Palme K. (1993). Release of Active Cytokinin by a -Glucosidase Localized to the Maize Root Meristem. Science New York Then Washington 262: 1051-1051.

Cartharius K., Frech K., Grote K., Klocke B., Haltmeier M., Klingenhoff A., Frisch M., Bayerlein M., and Werner T. 2005. MatInspector and beyond: Promoter analysis based on 
transcription factor binding sites. Bioinformatics 21:2933-2942. DOI:

380 10.1093/bioinformatics/bti473.

381 Chang C, Lu J, Zhang HP, Ma CX, and Sun G. 2015. Copy Number Variation of Cytokinin

382

383

384

385

386

387

388

389

390

391

392

393

394

395

396

397

398

399

400

401

402

403

404

405

406

407

408

Oxidase Gene Tackx4 Associated with Grain Weight and Chlorophyll Content of Flag Leaf in Common Wheat. PloS one 10: e0145970.

Chomczynski P., and Sacchi N. 2006. The single-step method of RNA isolation by acid guanidinium thiocyanate-phenol-chloroform extraction: Twenty-something years on. Nature Protocols 1:581-585. DOI: 10.1038/nprot.2006.83.

Daskalova S, McCormac A, Scott N, Van Onckelen H, and Elliott M. 2007. Effect of seedspecific expression of the ipt gene on Nicotiana tabacum L. seed composition. Plant Growth Regulation 51: 217-229.

Faiss M, Zalubìlová J, Strnad M, and Schmülling T. 1997. Conditional transgenic expression of the ipt gene indicates a function for cytokinins in paracrine signaling in whole tobacco plants. The Plant Journal 12: 401-415.

Falk A, and Rask L. 1995. Expression of a zeatin-o-glucoside-degrading $\beta$-glucosidase in Brassica napus. Plant Physiology 108: 1369-1377.

Feng DS, Wang HG., Zhang XS, Kong LR, Tian JC., and Li XF. 2008. Using an inverse PCR method to clone the wheat cytokinin oxidase/dehydrogenase gene TaCKX1. Plant Molecular Biology Reporter 26: 143-155.

Frébort I, Kowalska M, Hluska T, Frébortová J, and Galuszka P. 2011. Evolution of cytokinin biosynthesis and degradation. Journal of Experimental Botany 62: 2431-2452.

Galuszka P, Frébort I, Šebela M, and Peč P. 2000. Degradation of cytokinins by cytokinin oxidases in plants. Plant Growth Regulation 32: 315-327.

Goyal RK., Tulpan D., Chomistek N., González-Peña Fundora D., West C., Ellis BE., Frick M., Laroche A., Foroud NA. 2018. Analysis of MAPK and MAPKK gene families in wheat and related Triticeae species. BMC Genomics 19:178. DOI: 10.1186/s12864-0184545-9.

Hall TA. 1999. BioEdit: a user-friendly biological sequence alignment editor and analysis program for Windows 95/98/NT. Nucleic Acids Symposium Series 41:95-98. DOI: citeulike-article-id:691774. 
409 Higo K., Ugawa Y., Iwamoto M., and Korenaga T. 1999. Plant cis-acting regulatory DNA $410 \quad$ elements (PLACE) database: 1999. Nucleic Acids Research 27:297-300. DOI:

$411 \quad 10.1093 / \mathrm{nar} / 27.1 .297$.

412 Houba-Hérin N, Pethe C, d'Alayer J, and Laloue M. 1999. Cytokinin oxidase from Zea mays: 413 purification, cDNA cloning and expression in moss protoplasts. The Plant Journal 17: 615414626.

415 Hu B., Jin J., Guo AY., Zhang H., Luo J., and Gao G. 2015. GSDS 2.0: An upgraded gene 416 feature visualization server. Bioinformatics 31:1296-1297. DOI:

417 10.1093/bioinformatics/btu817.

418 Jameson P, McWha J, and Wright G. 1982. Cytokinins and changes in their activity during 419 420 421

Lee D., Redfern O., Orengo C. 2007. Predicting protein function from sequence and structure. Nature Reviews Molecular Cell Biology 8:995-1005. DOI: 10.1038/nrm2281. Wu H, Li Y, Cui Y, Guo X, Zheng S, Wang B, Yu K, Liang Q, Yang W, Lou X, Chen 
439

440

441

442

443

444

445

446

447

448

449

450

451

452

453

454

455

456

457

458

459

460

461

462

463

464

465

466

467

468

469

Zhang A, and Wang J. 2013. Draft genome of the wheat A-genome progenitor Triticum urartu. Nature 496: 87-90.

Livak KJ., and Schmittgen TD. 2001. Analysis of Relative Gene Expression Data Using RealTime Quantitative PCR and the $2^{-\Delta \Delta C t}$ Method. METHODS 25:402-408. DOI: 10.1006.

Lu J, Chang C, Zhang HP, Wang SX, Sun G, Xiao SH, and Ma CX. 2015. Identification of a Novel Allele of TaCKX6a02 Associated with Grain Size, Filling Rate and Weight of Common Wheat. PloS one 10: e0144765.

Ma X, Feng DS, Wang HG, Li XF, and Kong LR. 2011. Cloning and expression analysis of wheat cytokinin oxidase/dehydrogenase gene TaCKX3. Plant Molecular Biology Reporter 29: $98-105$.

Martin RC, Mok MC, and Mok DW. 1999. Isolation of a cytokinin gene, ZOG1, encoding zeatin O-glucosyltransferase from Phaseolus lunatus. PROCEEDINGS OF THE NATIONAL ACADEMY OF SCIENCES OF THE UNITED STATES OF AMERICA 96: 284289.

Miyahara T, Matsuba Y, Ozeki Y, and Sasaki N. 2011. Identification of genes in Arabidopsis thaliana with homology to a novel acyl-glucose dependent glucosyltransferase of carnations. Plant Biotechnology Journal 28: 311-315.

Miyawaki K, Tarkowski P, Matsumoto-Kitano M, Kato T, Sato S, Tarkowska D, Tabata S, Sandberg G, and Kakimoto T. 2006. Roles of Arabidopsis ATP/ADP isopentenyl transferases and tRNA isopentenyl transferases in cytokinin biosynthesis. PROCEEDINGS OF THE NATIONAL ACADEMY OF SCIENCES OF THE UNITED STATES OF AMERICA 103: $16598-16603$.

Mok DW, and Mok MC. 2001. Cytokinin metabolism and action. Annual Review of Plant Biology 52: 89-118.

Pačes V, Werstiuk E, and Hall RH. 1971. Conversion of N6-( $\Delta 2$-isopentenyl) adenosine to adenosine by enzyme activity in tobacco tissue. Plant Physiology 48: 775-778.

Paolacci AR, Tanzarella OA, Porceddu E, and Ciaffi M. 2009. Identification and validation of reference genes for quantitative RT-PCR normalization in wheat. BMC molecuar biology 10: 1 .

Qin H, Gu Q, Zhang J, Sun L, Kuppu S, Zhang Y, Burow M, Payton P, Blumwald E, and Zhang H. 2011. Regulated expression of an isopentenyl transferase gene (IPT) in peanut 
470

471

472

473

474

475

476

477

478

479

480

481

482

483

484

485

486

487

488

489

490

491

492

493

494

495

496

497

498

significantly improves drought tolerance and increases yield under field conditions. Plant and Cell Physiology 52: 1904-1914.

Sakakibara H. 2006. Cytokinins: activity, biosynthesis, and translocation. Annual Review of Plant Biology 57: 431-449.

Sakamoto T, Sakakibara H, Kojima M, Yamamoto Y, Nagasaki H, Inukai Y, Sato Y, and Matsuoka M. 2006. Ectopic expression of KNOTTED1-like homeobox protein induces expression of cytokinin biosynthesis genes in rice. Plant Physiology 142: 54-62.

Sasaki T, Matsumoto T, Yamamoto K, Sakata K, Baba T, Katayose Y, Wu J, Niimura Y, Cheng Z, and Nagamura Y. 2002. The genome sequence and structure of rice chromosome 1. Nature 420: 312-316.

Song J, Jiang L, and Jameson PE. 2012. Co-ordinate regulation of cytokinin gene family members during flag leaf and reproductive development in wheat. BMC plant biology 12: 1 .

Takei K, Sakakibara H, and Sugiyama T. 2001. Identification of genes encoding adenylate isopentenyl transferase, a cytokinin biosynthesis enzyme, in Arabidopsis thaliana. Journal of Biological Chemistry 276: 26405-26410.

Thompson JD., Higgins DG., and Gibson TJ. 1994. CLUSTAL W: Improving the sensitivity of progressive multiple sequence alignment through sequence weighting, position-specific gap penalties and weight matrix choice. Nucleic Acids Research 22:4673-4680. DOI: 10.1093/nar/22.22.4673.

Vyroubalová Š, Václavíková K, Turečková V, Novák O, Šmehilová M, Hluska T, Ohnoutková L, Frébort I, and Galuszka P. 2009. Characterization of new maize genes putatively involved in cytokinin metabolism and their expression during osmotic stress in relation to cytokinin levels. Plant Physiology 151: 433-447.

Yeh S-Y, Chen HW, Ng CY, Lin CY, Tseng TH, Li WH, and Ku MS. 2015. Downregulation of cytokinin oxidase 2 expression increases tiller number and improves rice yield. Rice 8: 1 .

Zalabák D, Pospíšilová H, Šmehilová M, Mrízová K, Frébort I, and Galuszka P. 2013. Genetic engineering of cytokinin metabolism: prospective way to improve agricultural traits of crop plants. Biotechnology Advances 31: 97-117. 
499 Zalewski W, Galuszka P, Gasparis S, Orczyk W, and Nadolska-Orczyk A. 2010. Silencing

500 of the $H v C K X 1$ gene decreases the cytokinin oxidase/dehydrogenase level in barley and

$501 \quad$ leads to higher plant productivity. Journal of Experimental Botany erq052.

502 Zalewski W, Gasparis S, Boczkowska M, Rajchel IK, Kała M, Orczyk W, and Nadolska-

503 Orczyk A. 2014. Expression patterns of $H v C K X$ genes indicate their role in growth and

504 reproductive development of barley. PloS one 9: e115729.

505 Zhang J, Liu W, Yang X, Gao A, Li X, Wu X, and Li L. 2011. Isolation and characterization

506 of two putative cytokinin oxidase genes related to grain number per spike phenotype in

$507 \quad$ wheat. Molecular Biology Reports 38: 2337-2347.

508 Zhang L, Zhang B, Zhou R, Gao L, Zhao G, Song Y, and Jia J. 2007. Cloning and genetic

509 mapping of cytokinin oxidase/dehydrogenase gene TaCKX2 in wheat. Acta Agronomica

$510 \quad$ Sinica 33:1419-1425.

511

512 
514

\section{Table legends}

516 Table 1 Previously assigned nomenclature of wheat cytokinin oxidase/dehydrogenase $(\mathrm{TaCKX})$ 517 gene family.

518

519 Table 2 Characteristic features of wheat $\operatorname{TaCKX}(\mathrm{a}), \operatorname{TaZOG}(\mathrm{b}), \operatorname{TaIPT}$ (c) and $\operatorname{Ta} G L U$ (d) gene 520 families.

521

522 Table 3 cis- regulatory elements in the promoter region of wheat $\operatorname{TaCKX}(\mathrm{a}), \operatorname{TaZOG}(\mathrm{b}), \operatorname{TaIPT}$ 523 (c) and $T a G L U$ (d) gene families.

524 
527 Figure legends

528

529 Figure 1 The unrooted phylogenetic tree of 13 TaCKX (A), seven TaZOG (B), nine TaIPT (C)

530 and 32 TaGLU (D) genes from wheat.

531 The tree was produced at amino acid level using neighbor joining method and bootstrapped at

5321000 replications. Newly identified genes are in red color.

533

534 Figure 2 Chromosome locations of TaCKX, TaZOG, TaIPT and TaGLU genes in wheat.

535 Wheat reference sequence 1.0 was used to develop the physical map of the wheat CK metabolic

536 genes.

537

538 Figure 3 The unrooted phylogenetic tree of $C K X(\mathrm{~A}), Z O G(\mathrm{~B}), I P T(\mathrm{C})$ and $G L U(\mathrm{D})$ genes

539 from Arabidopsis (At), rice (Os), maize $(\mathrm{Zm})$ and wheat $(\mathrm{Ta})$.

540 The tree was produced at amino acid level using neighbor joining method and bootstrapped at

5411000 replications. Newly identified genes are in red color.

542

543 Figure 4 Predicted gene structures of wheat $\operatorname{TaCKX}(\mathrm{A}), \operatorname{TaZOG}(\mathrm{B}), \mathrm{TaIPT}(\mathrm{C})$ gene

544 families and of newly identified $\operatorname{TaGLU}(\mathrm{D})$ genes.

545 Exons and introns are illustrated by filled boxes and single lines respectively. UTRs are shown in

546 blue color lines. Gene structures are developed using Gene Structure Display server

547 (http://gsds.cbi.pku.edu.cn).

549 Figure 5 Quantitative expression profiles of selected putative cytokinin regulatory genes

550 TaCKX, TaZOG, TaIPT, TaGLU in leaf (A \& B) and $\operatorname{root}(\mathrm{C} \& \mathrm{D})$ tissue of T. urartu 551 exposed to exogenously applied phyto-hormones treatment.

552 A \& C: Selected CK regulatory genes with relatively lower expression. B \& D: Selected CK

553 regulatory genes with relatively higher expression. Ta4045 gene primer was used as internal

554 control. Two technical and three biological replicates were used to reduce the error. Error bars

555 represent Standard Deviation $(n=3)$. 
558 Figure 6 Comparison among expression profiles of selected cytokinin regulatory genes

559 TaCKX, TaZOG, TaIPT and TaGLU, in leaf and root tissue of $T$. urartu exposed to

560 exogenously applied phyto-hormones treatment.

561 A: Selected CK regulatory genes with relatively lower expression. B: Selected CK regulatory

562 genes with relatively higher expression. Ta4045 gene primer was used as internal control. Two

563 technical and three biological replicates were used to reduce the error. Error bars represent

564 Standard Deviation $(\mathrm{n}=3)$.

565

566 


\section{Table $\mathbf{1}$ (on next page)}

Previously assigned nomenclature of wheat cytokinin oxidase/dehydrogenase (TaCKX) gene family. 
1 Table 1: Previously assigned nomenclature of wheat cytokinin oxidase/dehydrogenase

2 (TaCKX) gene family

\begin{tabular}{|c|c|c|}
\hline Sr\# & Gene name $^{a}$ & Previously assigned nomenclature \\
\hline 1 & $T a C K X 1$ & TaCKX1 (Feng et al., 2008; Song, Jiang \& Jameson, 2012) \\
\hline 2 & $\operatorname{TaCKX2}$ & TaCKX2 (JN381556.1 GenBank), TaCKX2.5 (Mameaux et al., 2012) \\
\hline 3 & $T a C K X 3$ & TaCKX6 (Song, Jiang \& Jameson, 2012), TaCKX8 (JQ925405.1 GenBank) \\
\hline 4 & TaCKX4 & TaCKX4 (Song, Jiang \& Jameson, 2012) \\
\hline 5 & $T a C K X 5$ & TaCKX5 (Lei, Baoshi \& Ronghua, 2008) \\
\hline 6 & $\operatorname{TaCKX7}$ & TaCKX8 (Song, Jiang \& Jameson, 2012) \\
\hline 7 & TaCKX8 & TaCKX11 (Song, Jiang \& Jameson, 2012) \\
\hline 8 & $\operatorname{TaCKX9}$ & TaCKX10 (Song, Jiang \& Jameson, 2012) \\
\hline 9 & TaCKX10 & TaCKX9 (Song, Jiang \& Jameson, 2012) \\
\hline 10 & $T a C K X 11$ & $\begin{array}{c}\text { TaCKX2 (Lei, Baoshi \& Ronghua, 2007), TaCKX3 (Ma et al., 2010; Song, } \\
\text { Jiang \& Jameson, 2012) }\end{array}$ \\
\hline 11 & $\mathrm{TaCKX} 12$ & TaCKX2.1 (Zhang et al., 2011), TaCKX6D (Zhang et al., 2012) \\
\hline 12 & $T a C K X 13$ & TaCKX2.2 (Zhang et al., 2011) \\
\hline 13 & $\mathrm{TaCKX} 14$ & TaCKX2.4 (Mameaux et al., 2012) \\
\hline
\end{tabular}




\section{Table 2 (on next page)}

Characteristic features of wheat TaCKX (a), TaZOG (b), TaIPT (c) and TaGLU (d) gene families. 
1 Table 2 Characteristic features of wheat $\operatorname{TaCKX}(\mathrm{a}), \operatorname{TaZOG}(\mathrm{b}), \operatorname{TaIPT}$ (c) and $\operatorname{TaGLU}(\mathrm{d})$

2 gene families.

3

(a) Cytokinin oxidase/dehydrogenase ( $T a C K X)$

\begin{tabular}{llccclc}
\hline & Genes & Length (aa) & PI & MW (kDa) & Subcell location & Glyco. sites \\
\cline { 2 - 6 } 1 & TaCKX1 & 524 & 8.68 & 56.9 & ER \& Vacuole & 5 \\
2 & TaCKX2 & 555 & 6.18 & 59.8 & ER \& Vacuole & 2 \\
3 & TaCKX3 & 523 & 6.28 & 57.7 & ER \& Vacuole & 0 \\
4 & TaCKX4 & 527 & 6.53 & 57.8 & ER \& Vacuole & 3 \\
5 & TaCKX5 & 531 & 6.03 & 57.8 & ER \& Vacuole & 2 \\
6 & TaCKX7 & 535 & 8.49 & 58.5 & ER \& Vacuole & 4 \\
7 & TaCKX8 & 528 & 5.62 & 57.2 & ER \& Vacuole & 0 \\
8 & TaCKX9 & 521 & 6.86 & 58.3 & ER \& Vacuole & 5 \\
9 & TaCKX10 & 532 & 6.1 & 58.0 & ER \& Vacuole & 3 \\
10 & $T a C K X 11$ & 516 & 5.93 & 55.7 & ER \& Vacuole & 0 \\
11 & TaCKX12 & 547 & 5.57 & 59.2 & ER \& Vacuole & 1 \\
12 & $T a C K X 13$ & 545 & 6.05 & 58.8 & ER \& Vacuole & 1 \\
13 & TaCKX14 & 552 & 5.56 & 59.4 & ER \& Vacuole & 1
\end{tabular}

(b) Zeatin O-glucosyltransferases (TaZOG)

\begin{tabular}{|c|c|c|c|c|c|c|}
\hline 1 & TaZOG1 & 491 & 5.99 & 53.4 & $\begin{array}{c}\text { Plasma } \\
\text { membrane }\end{array}$ & 2 \\
\hline 2 & TaZOG2 & 481 & 5.74 & 53.1 & Secreted & 0 \\
\hline 3 & TaZOG3 & 551 & 5 & 59.3 & $\begin{array}{c}\text { Plasma } \\
\text { membrane }\end{array}$ & 2 \\
\hline 4 & TaZOG4 & 529 & 5.43 & 56.3 & $\begin{array}{c}\text { Plasma } \\
\text { membrane }\end{array}$ & 1 \\
\hline 5 & TacisZOG1 & 467 & 5.87 & 50.8 & Secreted & 0 \\
\hline 6 & TacisZOG3 & 466 & 6.23 & 50.6 & Secreted & 0 \\
\hline 7 & TacisZOG4 & 528 & 6.93 & 57.5 & Secreted & 0 \\
\hline \multicolumn{7}{|c|}{ (c) isopentenyl transferases (TaIPT) } \\
\hline 1 & TaIPT1 & 292 & 5.23 & 31.6 & chloroplast & 0 \\
\hline 2 & TaIPT2 & 355 & 5.05 & 38.0 & chloroplast & 0 \\
\hline 3 & TaIPT3 & 369 & 9.24 & 39.2 & chloroplast & 0 \\
\hline 4 & TaIPT5 & 351 & 8.16 & 37.8 & chloroplast & 1 \\
\hline
\end{tabular}




$\begin{array}{lllllll}5 & \text { TaIPT6 } & 351 & 8.47 & 37.8 & \text { chloroplast } & 1 \\ 6 & \text { TaIPT7 } & 346 & 6.68 & 37.1 & \text { chloroplast } & 0 \\ 7 & \text { TaIPT8 } & 392 & 9.09 & 41.2 & \text { chloroplast } & 0 \\ 8 & \text { TaIPT9 } & 466 & 6.68 & 52.1 & \text { Cytoplasm } & 0 \\ 9 & \text { TaIPT10 } & 499 & 6.77 & 50.5 & \text { Cytoplasm } & 1\end{array}$

(d) wheat $\beta$-glucosidases (TaGLU)

\begin{tabular}{|c|c|c|c|c|c|c|}
\hline & Genes & Length (aa) & PI & MW (kDa) & subcell location & Glyco. sites \\
\hline 1 & TaGLU5 & 475 & 5.46 & 53.1 & vacuole & 4 \\
\hline 2 & TaGLU6 & 427 & 7.15 & 49 & chloroplast & 2 \\
\hline 3 & $T a G L U 7$ & 508 & 9 & 56.6 & chloroplast & 1 \\
\hline 4 & $T a G L U 8$ & 585 & 6.72 & 64.6 & chloroplast & 2 \\
\hline 5 & TaGLU9 & 532 & 6.9 & 59.5 & vacuole & 2 \\
\hline 6 & $T a G L U 11$ & 508 & 4.91 & 56.6 & vacuole & 3 \\
\hline 7 & $T a G L U 12$ & 519 & 6.93 & 58.6 & chloroplast & 4 \\
\hline 8 & $T a G L U 13$ & 508 & 5.7 & 57.5 & chloroplast & 1 \\
\hline 9 & $T a G L U 14$ & 519 & 6.79 & 59.5 & chloroplast & 2 \\
\hline 10 & $T a G L U 15$ & 430 & 5.35 & 48.4 & chloroplast & 1 \\
\hline 11 & $T a G L U 16$ & 511 & 6.12 & 57.8 & vacuole & 1 \\
\hline 12 & $T a G L U 17$ & 504 & 9.55 & 55.8 & chloroplast & 1 \\
\hline 13 & $T a G L U 19$ & 506 & 5.36 & 56.7 & vacuole & 2 \\
\hline 14 & $T a G L U 21$ & 473 & 5.4 & 52.4 & vacuole & 2 \\
\hline 15 & $T a G L U 22$ & 485 & 5.2 & 53.8 & vacuole & 2 \\
\hline 16 & $T a G L U 23$ & 477 & 5.6 & 53.4 & vacuole & 2 \\
\hline 17 & $T a G L U 24$ & 502 & 8.37 & 57.5 & chloroplast & 3 \\
\hline 18 & TaGLU26 & 448 & 6.67 & 51.5 & chloroplast & 4 \\
\hline 19 & $T a G L U 28$ & 525 & 8.72 & 59.4 & chloroplast & 4 \\
\hline 20 & TaGLU30 & 517 & 9.26 & 58 & vacuole & 3 \\
\hline 21 & $T a G L U 31$ & 503 & 6.05 & 56.5 & vacuole & 6 \\
\hline 22 & $T a G L U 32$ & 522 & 7.28 & 58.5 & vacuole & 1 \\
\hline 23 & $T a G L U 34$ & 515 & 6.92 & 58.4 & chloroplast & 4 \\
\hline 24 & TaGLU35 & 406 & 6 & 46.1 & chloroplast & 2 \\
\hline 25 & $T a G L U 38$ & 502 & 7.29 & 58.4 & chloroplast & 5 \\
\hline
\end{tabular}

$4 \mathrm{PI}=$ Isoelectric point,$\quad \mathrm{MW}=$ Molecular weight, $\quad$ Glyco. Sites $=$ Glycosylation sites $\mathrm{ER}=\quad$ Endoplasmic

5 reticulum

6 For TaGLU family, characteristic features of only newly identified genes are presented here.

7 PI \& MW predicted by ExPASy (http://web.expasy.org/compute pi/) 
8 Subcell location predicted by Softberry (http://www.softberry.com/)

9 Glyco. Sites predicted by NetNGlyc (http://www.cbs.dtu.dk/services/NetNGlyc/) 


\section{Table 3(on next page)}

cis- regulatory elements in the promoter region of wheat TaCKX (a), TaZOG (b), TaIPT (c) and TaGLU (d) gene families. 
2 Table 3 cis- regulatory elements in the promoter region of wheat $\operatorname{TaCKX}(\mathrm{a}), \operatorname{TaZOG}(\mathrm{b})$,

$3 \quad$ TaIPT (c) and $T a G L U$ (d) gene families.

4

5 (a) Cytokinin oxidase/dehydrogenase $(\mathrm{TaCKX})$

\begin{tabular}{|c|c|c|c|c|c|c|c|c|}
\hline & Auxin & $\mathbf{S A}$ & $\mathbf{A B A}$ & $\begin{array}{c}\text { Sulphu } \\
\text { r }\end{array}$ & $\begin{array}{c}\text { Drough } \\
\mathbf{t}\end{array}$ & Cold & Light & $\mathbf{G A}_{3}$ \\
\hline TaCKX1 & 4 & 4 & 5 & 1 & 9 & 2 & 1 & 1 \\
\hline$T a C K X 2$ & 0 & 0 & 7 & 4 & 8 & 4 & 0 & 1 \\
\hline$T a C K X 3$ & 1 & 1 & 1 & 1 & 9 & 2 & 3 & 0 \\
\hline$T a C K X 4$ & 5 & 5 & 20 & 9 & 22 & 10 & 2 & 1 \\
\hline$T a C K X 5$ & 1 & 1 & 4 & 4 & 10 & 0 & 2 & 0 \\
\hline$T a C K X 7$ & 6 & 5 & 7 & 6 & 5 & 6 & 2 & 3 \\
\hline TaCKX8 & 6 & 6 & 9 & 5 & 6 & 3 & 2 & 1 \\
\hline TaCKX 9 & 0 & 0 & 2 & 3 & 6 & 0 & 4 & 4 \\
\hline TaCKX10 & 2 & 2 & 7 & 1 & 6 & 2 & 0 & 2 \\
\hline TaCKX11 & 1 & 1 & 8 & 3 & 8 & 4 & 2 & 0 \\
\hline TaCKX12 & 5 & 5 & 7 & 4 & 10 & 4 & 0 & 0 \\
\hline TaCKX13 & 8 & 8 & 12 & 4 & 18 & 9 & 2 & 0 \\
\hline TaCKX14 & 0 & 0 & 6 & 4 & 11 & 4 & 0 & 1 \\
\hline
\end{tabular}

(b) Zeatin O-glucosyltransferases (TaZOG)

\begin{tabular}{|c|c|c|c|c|c|c|c|c|}
\hline TaZOG1 & 2 & 2 & 10 & 2 & 34 & 5 & 0 & 0 \\
\hline TaZOG2 & 2 & 2 & 5 & 2 & 9 & 0 & 2 & 0 \\
\hline TaZOG3 & 0 & 0 & 8 & 6 & 10 & 4 & 2 & 2 \\
\hline TaZOG4 & 10 & 10 & 15 & 6 & 20 & 6 & 1 & 0 \\
\hline $\begin{array}{c}\text { TacisZOG } \\
1\end{array}$ & 7 & 7 & 3 & 3 & 7 & 9 & 0 & 1 \\
\hline $\begin{array}{c}\text { Tacis } Z O G \\
3\end{array}$ & 4 & 4 & 2 & 2 & 6 & 0 & 2 & 0 \\
\hline $\begin{array}{c}\text { TacisZOG } \\
4\end{array}$ & 1 & 1 & 4 & 3 & 8 & 2 & 1 & 2 \\
\hline \multicolumn{9}{|c|}{ (c) isopentenyl transferases (TaIPT) } \\
\hline TaIPT1 & 2 & 2 & 6 & 2 & 6 & 2 & 1 & 2 \\
\hline TaIPT2 & 0 & 0 & 1 & 0 & 5 & 0 & 2 & 0 \\
\hline TaIPT3 & 0 & 0 & 0 & 1 & 3 & 5 & 0 & 1 \\
\hline TaIPT4 & 2 & 2 & 4 & 2 & 6 & 0 & 0 & 0 \\
\hline
\end{tabular}




$\begin{array}{lllllllll}\text { TaIPT6 } & 3 & 3 & 2 & 5 & 8 & 6 & 3 & 0 \\ \text { TaIPT7 } & 6 & 6 & 9 & 6 & 12 & 3 & 3 & 1 \\ \text { TaIPT8 } & 2 & 1 & 6 & 3 & 16 & 9 & 2 & 0 \\ \text { TaIPT9 } & 3 & 3 & 5 & 1 & 9 & 4 & 1 & 0 \\ \text { TaIPT10 } & 3 & 3 & 0 & 6 & 8 & 3 & 1 & 1\end{array}$

(d) wheat $\beta$-glucosidases (TaGLU)

\begin{tabular}{|c|c|c|c|c|c|c|c|c|}
\hline & Auxin & SA & $\mathbf{A B A}$ & $\begin{array}{c}\text { Sulphu } \\
\text { r }\end{array}$ & $\begin{array}{c}\text { Drough } \\
\mathbf{t}\end{array}$ & Cold & Light & $\mathbf{G A}_{3}$ \\
\hline TaGLU5 & 2 & 2 & 2 & 1 & 6 & 1 & 5 & 1 \\
\hline TaGLU6 & 4 & 4 & 7 & 4 & 6 & 8 & 1 & 0 \\
\hline TaGLU7 & 7 & 7 & 9 & 2 & 28 & 7 & 0 & 0 \\
\hline TaGLU8 & 5 & 5 & 4 & 2 & 8 & 6 & 0 & 0 \\
\hline TaGLU9 & 6 & 5 & 2 & 4 & 4 & 11 & 0 & 0 \\
\hline TaGLU11 & 1 & 1 & 3 & 3 & 11 & 3 & 3 & 0 \\
\hline TaGLU12 & 5 & 4 & 5 & 2 & 5 & 5 & 2 & 0 \\
\hline TaGLU13 & 1 & 1 & 8 & 2 & 22 & 1 & 1 & 0 \\
\hline TaGLU14 & 4 & 4 & 0 & 3 & 2 & 6 & 1 & 1 \\
\hline TaGLU15 & 3 & 2 & 5 & 2 & 12 & 2 & 0 & 3 \\
\hline TaGLU16 & 0 & 0 & 0 & 4 & 9 & 4 & 0 & 0 \\
\hline TaGLU17 & 5 & 5 & 7 & 1 & 11 & 13 & 0 & 1 \\
\hline TaGLU19 & 6 & 6 & 8 & 1 & 12 & 3 & 2 & 0 \\
\hline TaGLU21 & 2 & 2 & 1 & 3 & 5 & 1 & 3 & 2 \\
\hline TaGLU22 & 2 & 2 & 3 & 4 & 4 & 6 & 1 & 2 \\
\hline TaGLU23 & 3 & 3 & 20 & 0 & 12 & 16 & 1 & 1 \\
\hline TaGLU24 & 1 & 0 & 4 & 1 & 6 & 6 & 0 & 1 \\
\hline TaGLU26 & 2 & 2 & 7 & 1 & 17 & 2 & 2 & 0 \\
\hline TaGLU28 & 1 & 0 & 5 & 4 & 11 & 3 & 3 & 0 \\
\hline TaGLU30 & 2 & 2 & 8 & 1 & 11 & 8 & 0 & 0 \\
\hline TaGLU31 & 1 & 1 & 7 & 3 & 9 & 1 & 5 & 0 \\
\hline TaGLU32 & 4 & 4 & 7 & 4 & 6 & 4 & 0 & 0 \\
\hline TaGLU34 & 0 & 0 & 1 & 5 & 5 & 1 & 1 & 0 \\
\hline TaGLU35 & 2 & 2 & 2 & 2 & 6 & 2 & 1 & 1 \\
\hline TaGLU38 & 4 & 4 & 6 & 6 & 10 & 3 & 1 & 2 \\
\hline
\end{tabular}

6 Arabic numerals represent the number of repeats of cis-regulatory elements in the promoter region of cytokinin

7 metabolic gene families; whereas, 0 represents absence of specific cis-element.

8 For TaGLU family, cis-regulatory elements of only newly identified genes are presented here. 
9 PLACE library was used to predict the cis-elements, and Auxin, Salicylic acid (SA), Abscisic acid (ABA), 10 Sulphur, Drought, Cold, light and Gibberellic acid $\left(\mathrm{GA}_{3}\right)$ responsive cis-elements were given consideration. 
Figure 1

The unrooted phylogenetic tree of $13 \operatorname{TaCKX}(\mathrm{A})$, seven TaZOG (B), nine TaIPT (C) and $32 \mathrm{TaGLU}$ (D) genes from wheat.

The tree was produced at amino acid level using neighbor joining method and bootstrapped at 1000 replications. Newly identified genes are in red color.
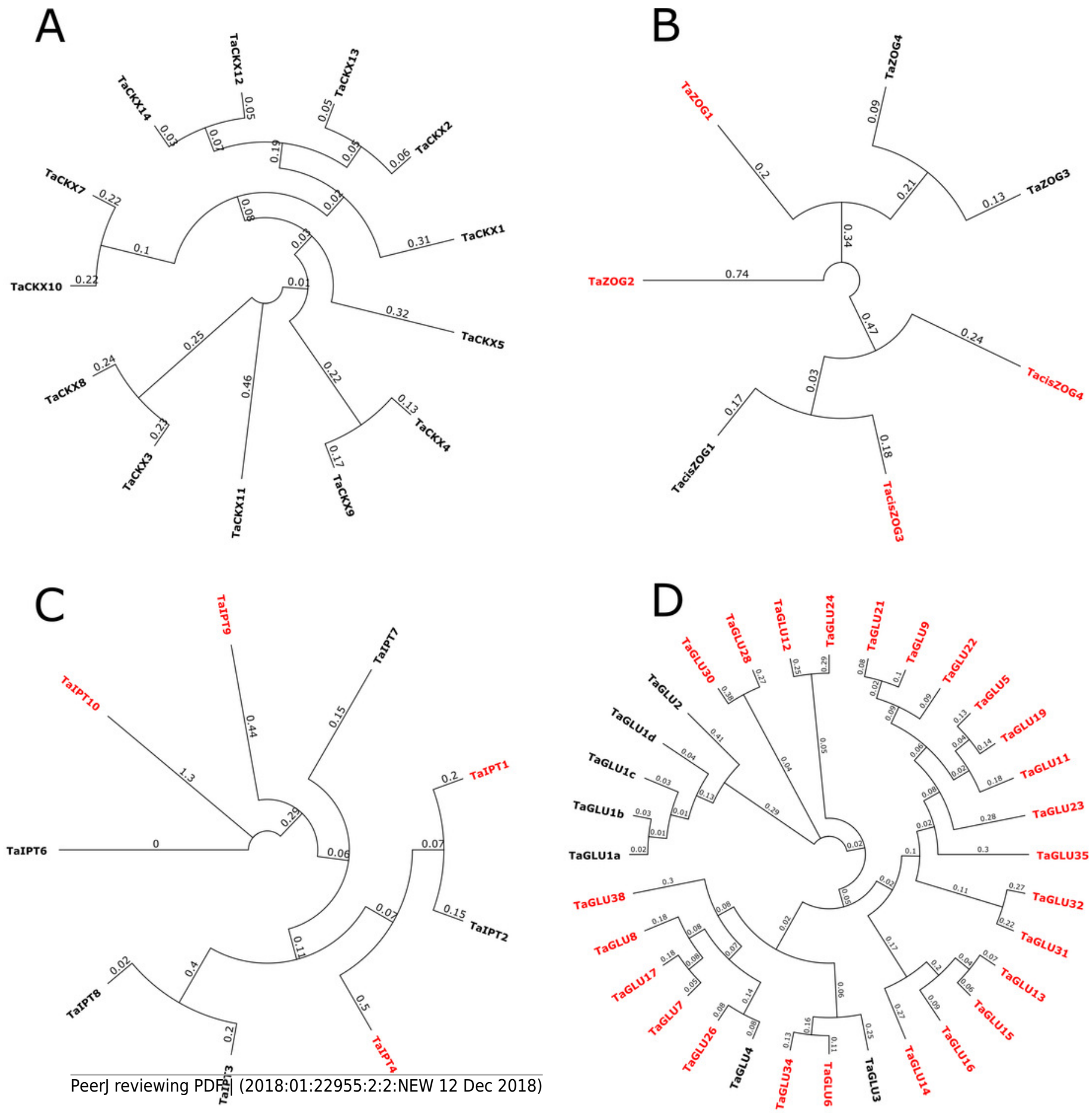
Figure 2

Chromosome locations of TaCKX, TaZOG, TaIPT and TaGLU genes in wheat.

Wheat reference sequence 1.0 was used to develop the physical map of the wheat CK metabolic genes. 
$\begin{array}{lllllllll}\text { Chr 1A } & \text { Chr 1B } & \text { Chr 1D } & \text { Chr 2A } & \text { Chr 2B } & \text { Chr 2D } & \text { Chr 3A } & \text { Chr 3B } & \text { Chr 3D }\end{array}$

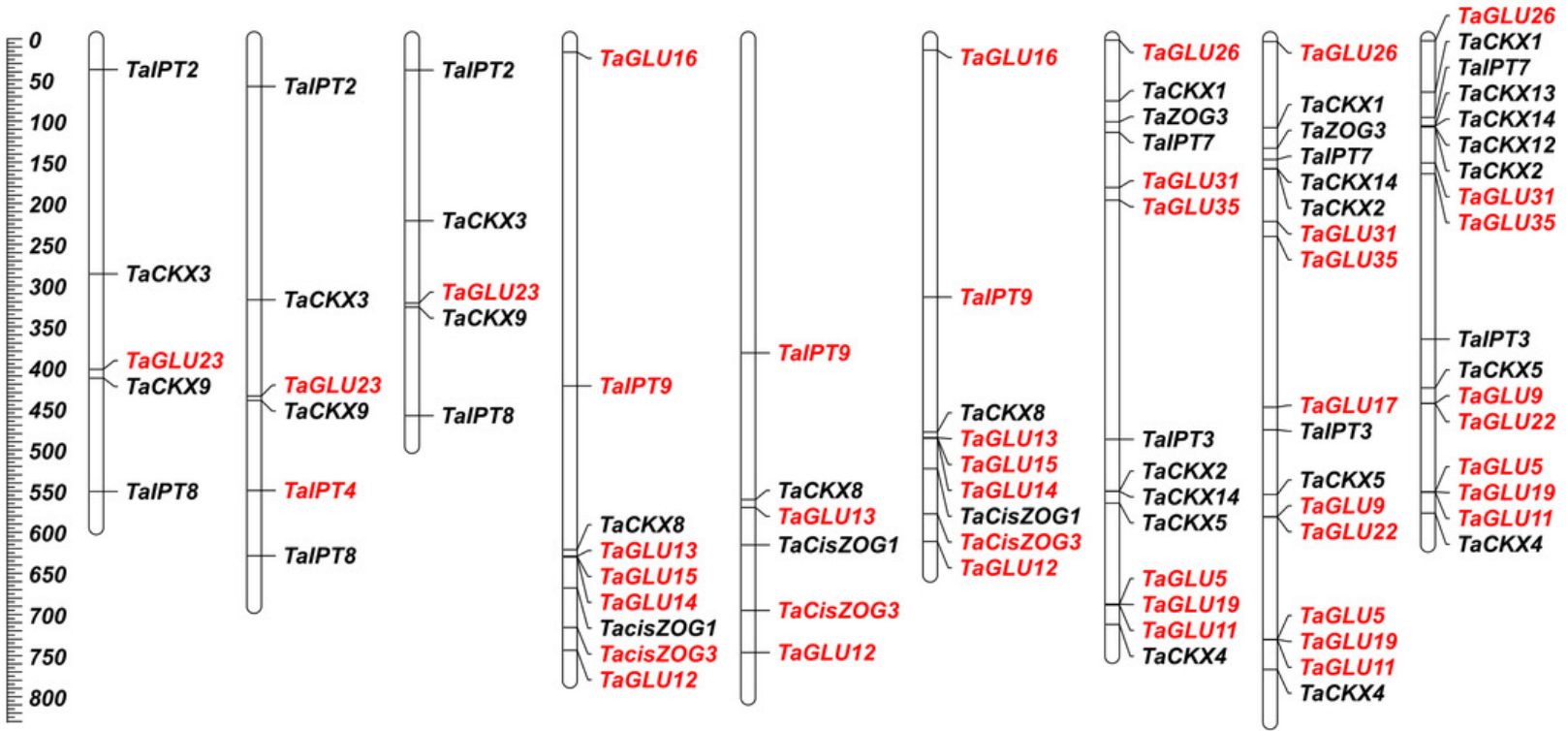

$\begin{array}{lllllllll}\text { Chr 4A } & \text { Chr 4B } & \text { Chr 4D } & \text { Chr 5A } & \text { Chr 5B } & \text { Chr 5D } & \text { Chr 6A } & \text { Chr 6B } & \text { Chr 6D }\end{array}$

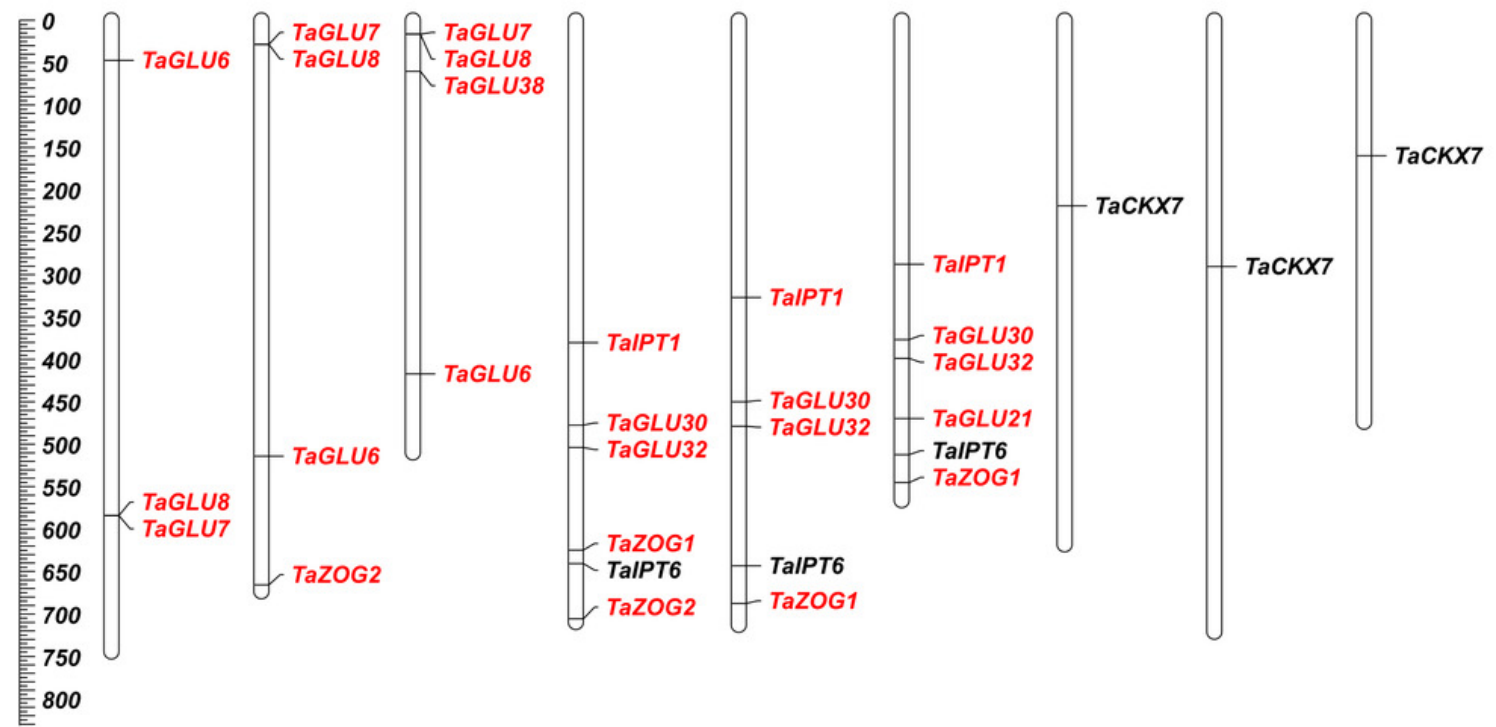

Chr 7A Chr 7B $\quad$ Chr 7D $\quad$ Chr Un

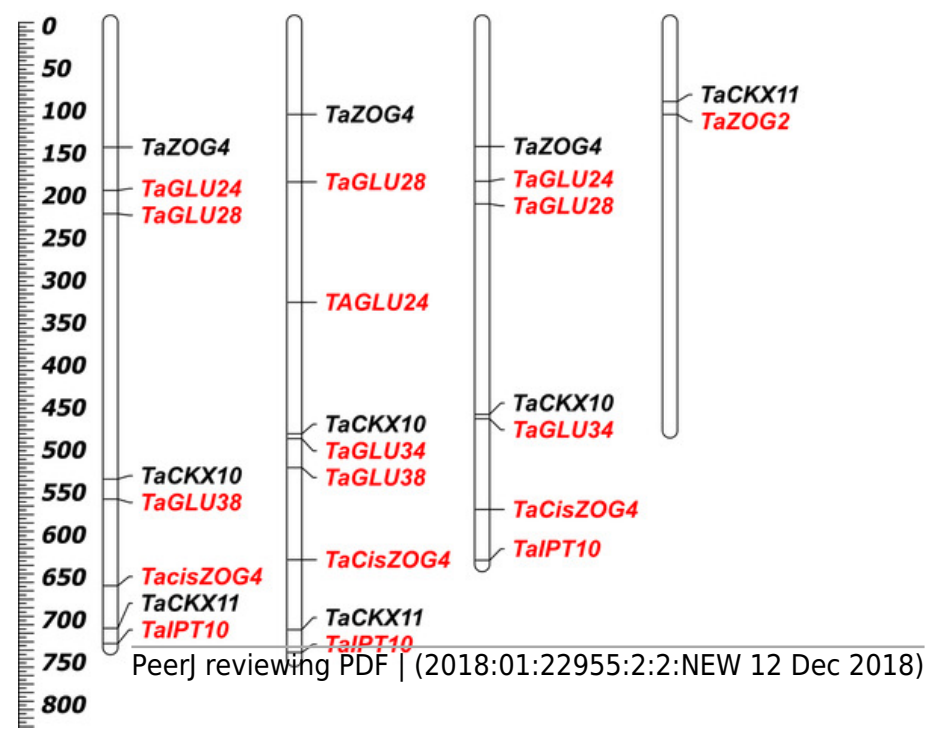




\section{Figure 3}

The unrooted phylogenetic tree of $C K X(\mathrm{~A}), Z O G(\mathrm{~B}), I P T(\mathrm{C})$ and $G L U(\mathrm{D})$ genes from Arabidopsis (At), rice $(\mathrm{Os})$, maize $(\mathrm{Zm})$ and wheat $(\mathrm{Ta})$.

The tree was produced at amino acid level using neighbor joining method and bootstrapped at 1000 replications. Newly identified genes are in red color.

*Note: Auto Gamma Correction was used for the image. This only affects the reviewing manuscript. See original source image if needed for review. 

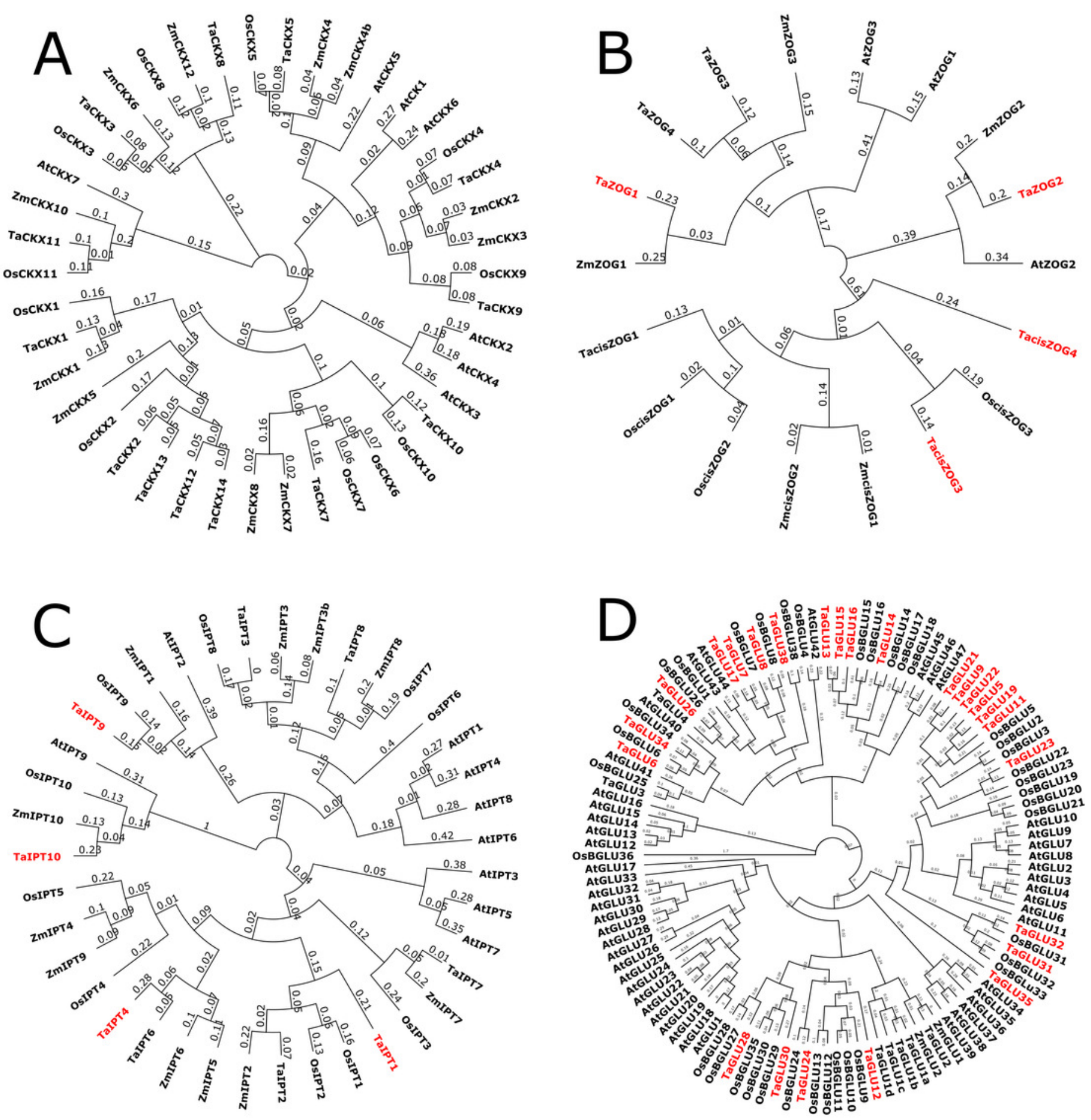
Figure 4

Predicted gene structures of wheat TaCKX (A), TaZOG (B), TaIPT (C) gene families and of newly identified TaGLU (D) genes.

Exons and introns are illustrated by filled boxes and single lines respectively. UTRs are shown in blue color lines. Gene structures are developed using Gene Structure Display server (http://gsds.cbi.pku.edu.cn). 


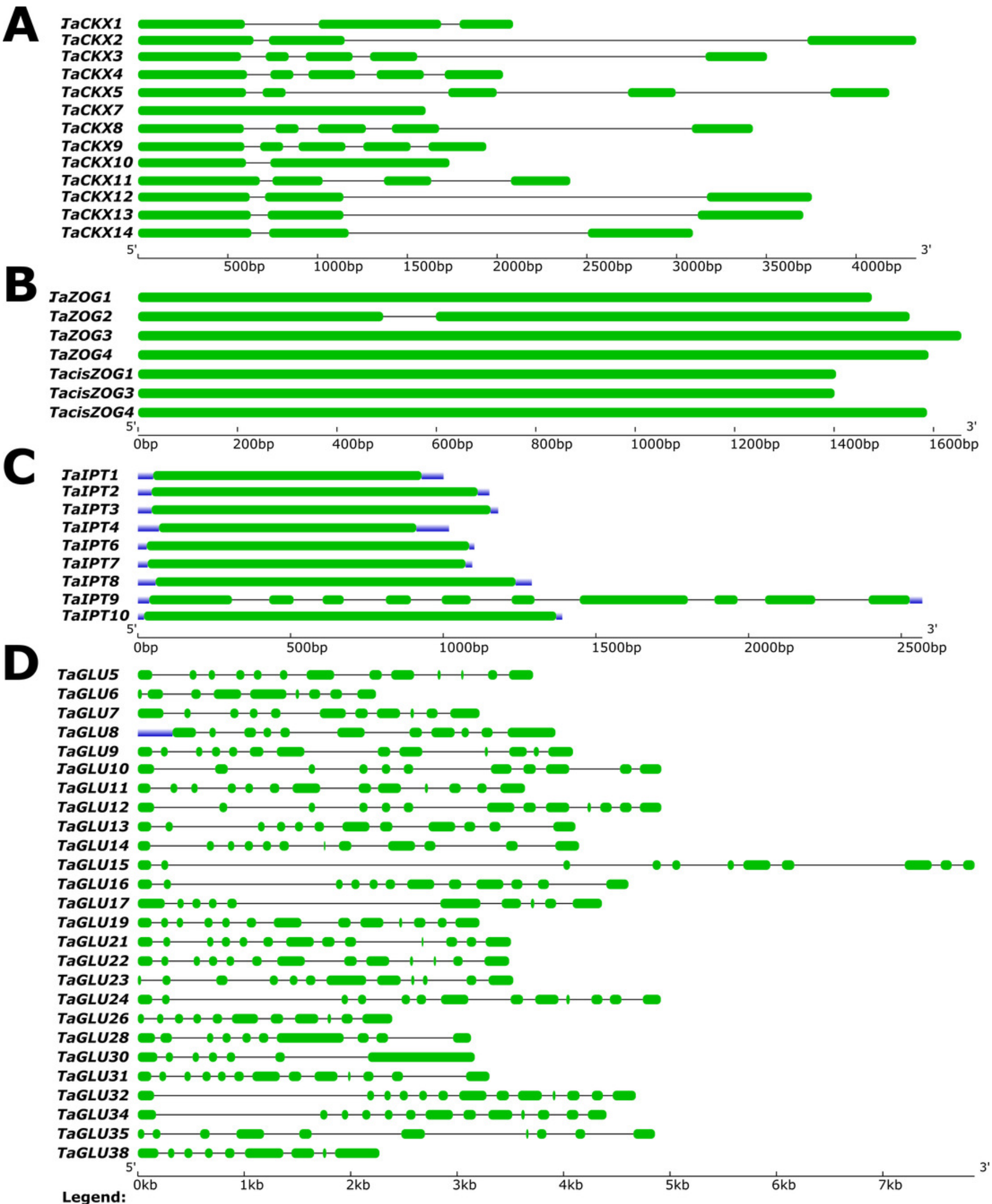

Legend:

Exon - upstream/ downstream - Intron 


\section{Figure 5}

Quantitative expression profiles of selected putative cytokinin regulatory genes TaCKX, TaZOG , TaIPT , TaGLU in leaf (A) and root (B) tissue of $T$. urartu exposed to exogenously applied phyto-hormones treatment.

A \& C: Selected CK regulatory genes with relatively lower expression. B \& D: Selected CK regulatory genes with relatively higher expression. Ta4045 gene primer was used as internal control. Two technical and three biological replicates were used to reduce the error. Error bars represent Standard Deviation $(n=3)$.
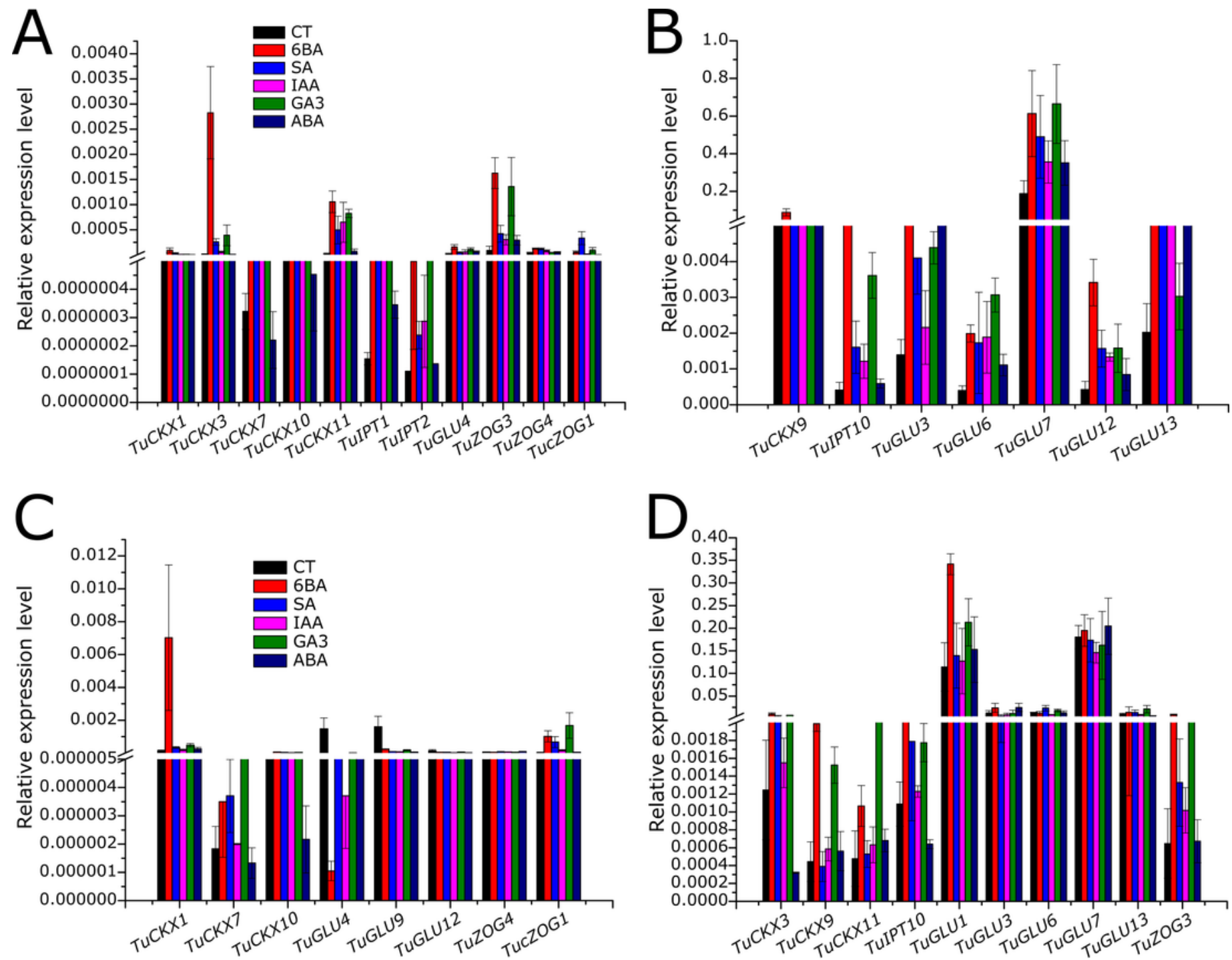


\section{Figure 6}

Comparison among expression profiles of selected cytokinin regulatory genes $T a C K X$, TaZOG, TaIPT and TaGLU, in leaf and root tissue of $T$. urartu exposed to exogenously applied phyto-hormones treatment.

A: Selected CK regulatory genes with relatively lower expression. B: Selected CK regulatory genes with relatively higher expression. Ta4045 gene primer was used as internal control. Two technical and three biological replicates were used to reduce the error. Error bars represent Standard Deviation $(n=3)$.
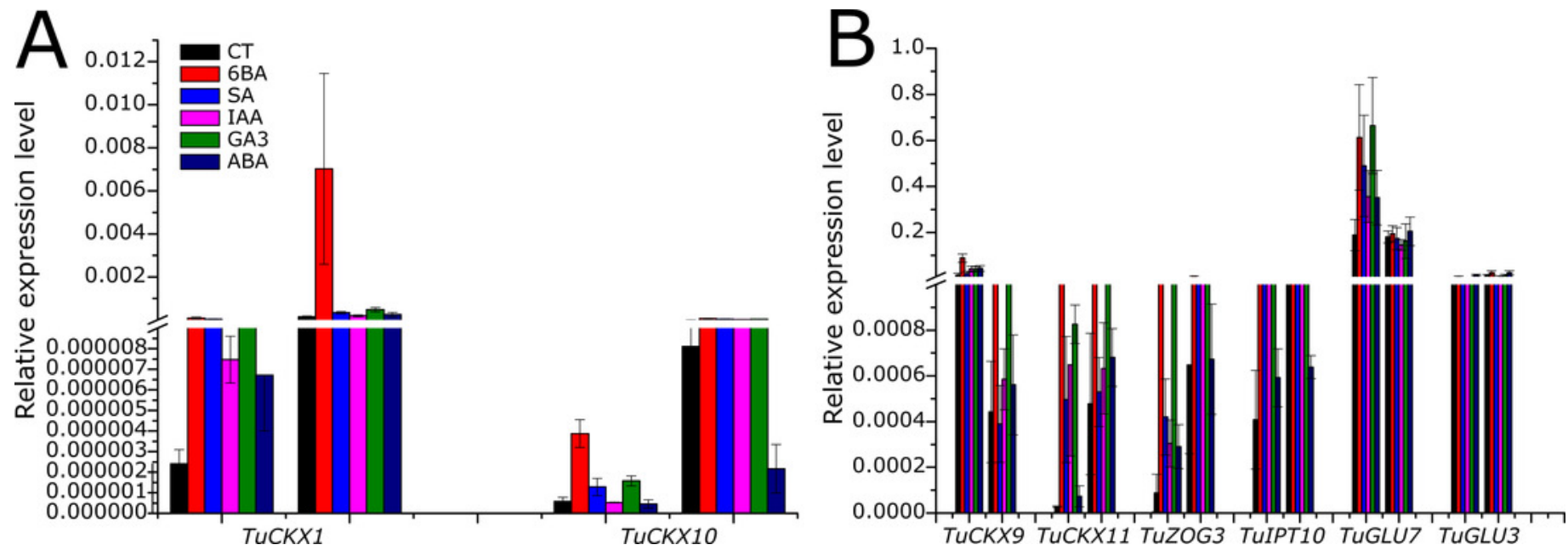